\title{
Current nutrition related practices in paediatrics throughout the UK and Ireland: The Children's Nutrition Survey, a pilot study
}

\author{
A. M. Carey, D. McClelland, H. McCarthy and H. McNulty \\ Northern Ireland Centre for Food and Health, University of Ulster, Coleraine BT52 1SA
}

Childhood growth and nutrition is internationally recognised as an area of importance in every child's development. Malnutrition is defined as a state of deficiency, excess or imbalance of nutrition which has an adverse affect on bodily function ${ }^{(1)}$. Adult under-nutrition is well recognised and extensively researched, leading to the development of guidelines, policies and nutrition screening tools to address the problem $^{(2-4)}$. However, there is a lack of similar research in paediatric practice. Under-nutrition in children remains a concern with estimates that $8-79 \%$ of hospitalised children are at risk of under-nutrition ${ }^{(5)}$. As under-nutrition gains greater recognition by health care professionals, the demands on dietetic services are expected to increase, however, there are currently no measures in place by which to monitor this. The aim of the present study was to examine current dietetic and nutrition practices in paediatric centres across the UK and Ireland.

The Children's Nutrition Survey was undertaken during January and February 2010. Hospitals were approached through publications in Dietetics Today, the Paediatric Group of the British Dietetic Association or by direct contact with the centres. Participating centres were asked to complete a 2-page questionnaire regarding services and practices within their centres. This questionnaire was adapted, with permission, from the BAPEN Adult Nutrition Screening Week 2010 questionnaire.

A total of 27 centres participated in the survey: 7 specialist paediatric hospitals and 20 district general/single wards. Of these 13 (48\%) hospitals reported the presence of a nutrition support team or nutrition steering committee. Only 8 centres could define their referral rates (the percentage of referrals to dietetic services from total number of in-patients), of which 5 defined their rate as falling within the lowest quartile of $0-25 \%$. Most centres reported that they were not currently using nutrition screening tools. Nutrition related information was routinely included in the discharge plan of only $6(22 \%)$ centres surveyed. Of note, centres that reported having a nutrition support team or steering committee tended to be more likely to record height on admission; however, this was not found to be statistically significant as a result of the small sample size.

\begin{tabular}{|c|c|c|c|c|}
\hline & $\begin{array}{l}\text { Weight taken on } \\
\text { admission } n(\%)\end{array}$ & $\begin{array}{l}\text { Height taken on } \\
\text { admission } n(\%)\end{array}$ & $\begin{array}{l}\text { Nutrition Practices } \\
\text { Audited } n(\%)\end{array}$ & $\begin{array}{l}\text { Staff trained on nutrition } \\
\text { topics/referral criteria }\end{array}$ \\
\hline Nutrition support team/steering committee $(n=13)$ & $11(85)$ & $4(31)$ & $8(62)$ & $12(44)$ \\
\hline No nutrition support team/steering committee $(n=14)$ & $13(93)$ & $0(0)$ & $1(7)$ & $9(64)$ \\
\hline
\end{tabular}

In conclusion, this study highlights the need for further research into nutrition related practices within paediatric health care centres across the UK and Ireland. The current study will contribute to future research examining how paediatric dietetic services adapt and deal with increasing demands on their services to provide evidence-based practice and quality dietetic services.

1. Elia M (2003) Screening for Malnutrition: A Multidisciplinary Responsibility. Development and Use of the 'Malnutrition Universal Screening Tool' ('MUST') for Adults. Malnutrition Advisory Group (MAG). Redditch: BAPEN.

2. Lanigan J, Barber S \& Singhal A (2010) Proc Nutr Soc 69, 204-210

3. Gerasimidis K, Drongitis P, Murray L et al. (2007) Eur J Clin Nutr 7, 916-921.

4. Vellas B, Guigoz Y, Garry PJ et al. (1999) Nutrition 15, 116-122.

5. Stratton RJ, Green CJ \& Elia M (2003) Disease-Related Malnutrition: An Evidence Based Approach to Treatment. Wallingford, UK: CAB International.

6. Agostoni C, Axelson I, Colomb V et al. (2005) The need for nutrition support teams in paediatric units: a commentary by the ESPGHAN Committee on Nutrition. J Pediatr Gastroenterol Nutr 41, 8-11. 